\title{
REFLEXÕES SOBRE A PRÁTICA DO ALEITAMENTO MATERNO.
}

Isilia Aparecida Silva*

SILVA,I.A. Reflexões sobre a prática do aleitamento materno: Rev.Esc.Enf.USP,v.30, n.1, p. 58-72, abr. 1996.

O trabalho traz uma análise sobre o aleitamento materno, fazendo reflexões sobre os indicadores determinantes da situação atual, buscando identificar os elementos fins e meios para atingir o cenário idealizado para o futuro da prática do amamentar.

UNITERMOS: Aleitamento materno. Amamentação.

O interesse pela efetiva inserção da prática de amamentar na população suscita, por parte dos orgãos governamentais, organizações não governamentais e, principalmente profissionais da área da saúde, as mais diferentes estratégias com vistas a tornar mais freqüente e duradoura a prática da amamentação.

Como um tema amplo e da maior importância, a situação da amamentação indica a necessidade de estabelecer metas para o futuro, buscar uma forma de preparar, no presente, os caminhos que nos conduzam aos objetivos propostos, por conseguinte, devemos considerar o passado e a situação atual da prática do amamentar.

Dentro desta perspectiva, consideramos válido fazer uma análise da amamentação, que implique na construção de uma base de conhecimento capaz de nos levar a encontrar ou validar propostas eficientes para a transformação da situação atual da prática do amamentar procurando distinguir fins e meios e valorizando-se mais os aspectos qualitativos do que os quantitativos.

Compreendemos a necessidade de encontrar um caminho que nos leve a enxergar o futuro que se deseja, da prática do amamentar, a partir de

* Enfermeira. Professor. Doutor do Departamento de Enfermagem Materno-Infantil e Psiquiátrica da Escola de Enfermagem da Universidade de São Paulo. 
observação e análise do presente para identificar os elementos que estão impedindo o alcance das metas já propostas. Para este fim, é imprescindível processar-se o estudo do passado, sua evolução até o presente, identificandose indicadores de projeção que possam ser aplicados aos possíveis cenários idealizados para o futuro.

Tomando a trajetória do aleitamento materno através dos tempos como um elemento de análise, este nos permite avaliar como as diversas culturas têm se comportado em relação a esse processo.

A despeito do valor atribuído ao leite materno e aos predicativos da amamentação como fenômeno biológico e suas inúmeras virtudes como fator de desenvolvimento afetivo entre a mulher e seu filho, do aleitamento materno vem apresentando ao longo da hist6ria da humanidade, variações quanto à freqüência e duração, nas mais diversas sociedades. Fato este que demonstra que as dificuldades encontradas para manutenção da prática da amamentação não é um problema apenas do nosso tempo, ou deste século.

Para os humanos, este parece ser um comportamento, que, embora considerado natural, está baseado em parte no aprendizado e na experiência e, principalmente, desenvolvido pela convivência com a situação da prática no ambiente familiar (FADUL et al,1983;SEPÚLVEDA et al,1983).

Segundo SILVA(1990), a amamentação assume significados diferentes entre os vários povos, sendo um comportamento social mutável conforme as épocas, costumes, sugerindo um hábito preso aos determinantes sociais e às manifestações da cultura.As concepções e valores, assimilados no processo de socialização, influem na prática da amamentação, tanto quanto o equilíbrio biologico e funcionamento hormonal da mulher. Esse autor ainda coloca que "cada sociedade, em determinada fase de sua história, cria percepções e construções culturais sobre o aleitamento materno, que se traduzem em saberes próprios". Afirma, ainda, que dependendo da constituição econômicosocial, são construídas, pela própria sociedade, referências específicas sobre a amamentação. Isto nos leva a compreender porque a amamentação apresenta comportamentos flutuantes no decorrer da historia da humanidade.

Observa-se que o esquema alimentar do recém-nascido tem sido muito variável, dependendo de cada época, estando muito mais embasado em hábitos culturais e sociais do que propriamente em argumentos científicos.

Considera-se que o homem utilize leite de animais e seus derivados há aproximadamente 8 milênios e, provavelmente, o tenha introduzido na alimentação do lactente por volta desse tempo, portanto, o que indica que o uso de outros alimentos, além do leite humano, está presente na alimentação de crianças em quase toda a história da humanidade. Achados arqueologicos, datados dos séc.V e VII, sugerem que os lactentes gregos recebiam alimentos de outras fontes além do leite materno, por meio de vasilhas de barro encontradas em tumbas de recém-nascidos daquela época. Da mesma forma, 
sabe-se da utilização do leite de cabras para recém-nascidos egípcios no séc IV a.C.(MOTA, 1990)

Historicamente, o grande período negro da prática do aleitamento ocorreu, em especial, durante os séculos XVII e XVIII com a adoção de amas de leite pelas mulheres aristocratas e burguesas, que consideravam o ato de amamentar ridículo e repugnante, sendo esse comportamento tomado como exemplo pelas mulheres das classes menos favorecidas (BADINTER, 1985).

No entanto, as amas de leite já existiam muito antes desse periodo, pois na época de Julio César sabe-se que era comum o uso de escravas para amamentar os filhos dos nobres sendo que as escravas nutrizes tinham um preço maior no mercado (MOTA, 1990).

No final do século XVIII, o leite de animais era oferecido às crianças em chifres. Tal fato já era prática instituída em alguns países da Europa, principalmente na Alemanha, Rússia e França. No início do século passado essa prática logo tornou-se freqüente e com resultados desastrosos, pois 7 entre 10 crianças alimentadas dessa forma morriam antes de completar um ano de idade. Na metade do século XIX era possível encontrar-se alimentos infantis no mercado e o leite de vaca passou a ser adotado quase que rotineiramente, pelas clínicas pediátricas, como alimento suplementar para os lactentes,principalmente na França. (CAVALCANTI, 1982; BADINTER, 1985).

A criança abandonada começou a ser um sério problema no sec.XVIII. Havia uma insensibilidade e indiferença pública à prática do infanticídio. Há evidências de que a morte infantil era decorrente de negligência, crueldade e doenças. $O$ aleitamento artificial era um contribunte em potencial para a mortalidade infantil, através do qual o lactente contraía doenças pelo leite contaminado e pela água com que se preparava a" mamadeira", ou ainda, era contaminado pelas amas de leite doentes (DONAHUE, 1985).

No final do séc.XVIII, os índices de mortalidade e situação de abandono das crianças à sua proppria sorte e as amas de leite mercenárias chegou ao ponto de suscitar entre as autoridades, a necessidade de uma intervenção no comportamento dos pais em relação aos filhos recém,-nascidos.

Foi quando iniciou-se então, campanhas em favor do cuidado da criança pela própria mãe no seio da família, e principalmente, as recomendações de que a própria mãe amamentasse seu filho. A criança passa a ser vista como o futuro adulto e uma das maneiras de se garantir que essa criança pudesse sobreviver e atingir a idade adulta, seria em primeira instância, cuidando de sua alimentação e conseqüentemente preservando sua saúde, sendo cuidada junto a família (BADINTER, 1985). Inicia-se uma nova era de concepção familiar fortalecendo o aleitamento materno como papel importante a ser desempenhado pela mulher em favor da sobrevivência da criança.

Temos, assim, a retomada ao aspecto simbólico da amamentação 
como uma conseqüência natural da maternidade, do dever e instintos de amor maternos.

No séc. XIX, torna-se presente o respaldo científico ao aleitamento materno, que aliado às demais concepções morais, religiosas, naturalísticas e higiênicas, exalta o leite humano e a amamentação como elementos integrantes e essenciais para a saúde e bem-estar da criança.

O desenvolvimento tecnológico e científico alcançado no princípio deste século, como a pasteurização, favoreceram a introdução do leite de vaca diluído na alimentação da criança. $\mathrm{O}$ advento do leite em pó permitiu que as indústrias de alimentos oferecessem fórmulas lácteas para crianças em diferentes idades, e, sua acessibilidade a praticamente todas as classes sociais, tornou bastante difundida a prática da mamadeira. As empresas não pouparam esforços para o avanço tecnológico, procurando oferecer para o mercado um produto substitu to do leite materno que tornasse dispensável a presença da mãe junto ao filho (RAMOS NETO et al,1978; GOLDENBERG,1988).

A diminuição na prática da amamentação parece estar relacionada, entre outras causas, com a migração da população rural para as cidades durante a Revolução Industrial, que determinou grandes transformações sociais, principalmente para a mulher que passou a trabalhar nas industrias, permanecendo longos períodos fora de casa dificultando e quase impossibilitando a continuidade da amamentação (HARDY;OSIS, 1991).

A adoção do leite indus trializado na alimentação dos lactentes mostravase crescente até meados da década de 70, apesar de aparentemente manterse a crença do leite materno como sendo o melhor alimento. Naquela década, apenas uma parcela das crianças era amamentada ao seio e, por períodos muito curtos que duravam em média de 1 a 3 meses. O leite em pó firmou-se junto à população e profissionais da área da saúde, como alimento considerado capaz de suprir as necessidades do lactente. A ampla propaganda desses produtos, em conjunto com o apoio dos profissionais, contribuiu fortemente para o declínio da prática do aleitamento materno (GOLDENBERG, 1988; SILVA, 1990).

Como conseqüência desse comportamento, a mortalidade infantil passou a apresentar altas taxas associadas, então, ao desmame precoce, principalmente nos grupos mais pobres dos países não desenvolvidos (GOLDEMBERG, 1988).

Alguns trabalhos desenvolvidos nas décadas de 70 e 80 retrataram o perfil do aleitamento materno em nosso meio, e seus resultados traduziram a situação daquela época em relação à pratica do amamentar.

Uma pesquisa realizada no período entre 1973-74 com crianças moradoras no município de São Paulo revelou que 35,6\% eram amamentadas por três meses ou mais, sendo que a duração mediana da amamentação correspondia a 28 dias (SIGULEN;TUDISCO,1980). Um segundo estudo 
realizado em 1981 com crianças de até oito meses de idade, no município de São Paulo, constatou que $36,5 \%$ das crianças recebiam aleitamento materno exclusivo até o primeiro mês de vida, enquanto que apenas $7,2 \%$ das crianças eram amamentadas exclusivamente aos dois meses de idade, sendo a duração média do aleitamento materno de 43,9 dias (BERQUO et al 1984). Considerando os ditames científicos de que a criança deve ser amamentada pelo menos até aos seis meses de idade,observa-se que em ambos os estudos, os resultados retratam uma situação na qual a duração da amamentação era muito pequena, caracterizando o desmame precoce dessa população de crianças.

Com a percepção da situação da saúde infantil e com o intuito de reverter este processo de predomínio da alimentação do lactente por leite industrializado, foram feitos estudos e campanhas que procuraram estabelecer estratégias para demonstrar a importância do aleitamento materno e promover a manutenção de sua prática.

O grande movimento pró-amamentação inicia-se em 1974, na 27a. Assembléia da OMS, quando foi feito o alerta aos países membros sobre a situação do declínio da prática do aleitamento materno e suas conseqüências nas várias regiões do mundo, apontando entre as causas a influência dos fatores sócio-culturais e a divulgação dos alimentos infantis industrializados (ORGANIZACION MUNDIAL DE LA SALÚD, 1974).

No entanto, só em 1980, retomou-se a discussão do tema e na 33a.Assembléia Mundial de Saúde, países membros adotaram as recomendações da Reunião Conjunta da Organização Mundial da Saúde e Fundo das Nações Unidas para a Infância sobre a alimentação para lactentes e crianças na fase da primeira infância. Nesta ocasião, destacou-se a necessidade do estímulo, fomento e apoio às práticas do aleitamento materno, assim como a promoção da saúde das mulheres em fase de amamentação. Considerou-se, ainda, a necessidade de estabelecer critérios para auxiliar a legislação dos governos sobre a regulamentação da comercialização dos alimentos infantis industrializados produzidos no próprio país ou importados (ORGANIZACION MUNDIAL DE LA SALÚD, 1980, ORGANIZACION MUNDIAL DE LA SALÚD, 1981).

No Brasil, a partir de 1981, o Governo Federal deu início à implantação do Programa Nacional de Incentivo ao Aleitamento Materno através do INSTITUTO NACIONAL DE ALIMENTAÇÃO E NUTRIÇÃO em convênio com a UNICEF. As estratégias deste programa visavam a execução de atividades de educação e treinamento de profissionais da saúde, reorganização dos serviços de atendimento à mulher e lactente, controle da publicidade e distribuição dos alimentos infantis industrializados e legislação específica sobre o trabalho da mulher (BRASIL,1982).

A ideologia, contida nas campanhas de incentivo ao aleitamento 
materno, proclama ser esta uma forma natural da mãe alimentar seu filho, considerada como resposta biológica e instintiva, motivada pelo amor materno.Coloca a mãe como responsável pela amamentação e pelas supostas conseqüências da sua ausência na saúde da criança, tanto física como emocional, reduzindo as questões sociais extremamente problemáticas que enfrentamos à questões individuais, jogando sua solução e responsabilidade para a mulher, de forma opressiva e violenta, mesmo que sutil e disfarçada.(MOTA, 1990)

As mensagens dirigidas as mulheres, no que diz respeito ao valor e importância da amamentação, têm uma abordagem superficial, apelativa para os sentimentos e instintos materno, não nos parecendo atender ou respeitar as necessidades da mulher.Considerando, principalmente, que a mensagem é única e tenta atingir mulheres de diferentes classes sociais que apresentam sua especificidade em suas experiências de amamentar, em diferentes contextos, e muitas vezes apresentam dificuldades para decodificar e assimilar os conteúdos.

Nas mensagens das campanhas, geralmente, não são abordadas as possíveis intercorrências e as dificuldades da amamentação, salientando-se apenas a sua importância biologica e emocional para a mãe e principalmente, para o recém-nascido. Isso, a nosso ver, não constitui, em absoluto, a garantia para o sucesso da amamentação. No entanto, é importante salientar que, decorridos praticamente 20 anos desde o início dos movimentos próaleitamento materno, embora algumas pesquisas demonstrem uma discreta tendência ao retorno da prática do amamentar, não é possível negar que a situação da amamentação ainda está longe daquela considerada ideal, principalmente nos grandes centros urbanos de países como o Brasil (BRASIL, 1992, BI'TTENCOURT et al,1993, MONCAU et al,1993).

A situação atual, além de não ser o panorama ideal, retrata uma desigualdade de recursos, de investimentos e de uma filosofia assistencial, em serviços, que assegurem as condições para a amamentação.

Embora seja imprescindível reconhecer os esforços e o investimento feitos ao longo desses anos, retratados pelas campanhas de aleitamento, fazse necessário admitir que seu papel tem sido enfraquecido pela falta de estrutura assistencial à mulher e seu filho nas questões da amamentação.

Diante de tantas diferenças regionais, torna-se difícil traçar um perfil da real situação do aleitamento materno. Observa-se que essa prática é amplamente favorecida quando a população se encontra próxima ou de alguma forma assistida por serviços de saúde que tenham uma atuação efetiva nos processos de incentivo ao aleitamento, vinculados, em sua maioria, a projetos acadêmicos, ou motivados pelo interesse e esforço pessoal dos profissionais ali envolvidos(MONCAU et al, 1993; BI'T'TENCOURT et al,1993; TERUYA et al, 1992). 
Ao considerarmos a trajetória do aleitamento materno, constatamos que os fatores possíveis de serem identificados, ao longo desse tempo, como dificultadores dessa prática, estão ligados a uma postura cultural, que envolve não apenas a decisão materna, mas o efeito das instituições e dos profissionais envolvidos, os interesses econômicos, acrescidos da evolução social pela qual a mulher e a família têm passado.É preciso reconhecer que, principalmente em questões como esta, que visa uma mudança de hábitos sociais, aplicar a teoria na prática é um processo que requer tempo e persis tência, sendo, muitas vezes difícil. É preciso considerar que a amamentação é um comportamento que, ao longo dos anos, adquiriu um perfil social próprio, refletido na criação de um padrão cultural de alternativas para alimentar o recém-nascido.

A partir das lições do passado, os avanços no sentido de se efetivar as ações pró-amamentação têm se tornado mais concretas. Uma das medidas, que vem combater concretamente um dos elementos prejudiciais à amamentação, e a NORMA BRASILEIRA PARA COMERCIALIZAÇÃO DE ALIMENTOS PARA LACTENTES, sendo esta, um instrumento para fomentar e proteger a amamentação em nosso país. A NORMA BRASILEIRA PARA COMERCIALIZAÇÃO DE ALIMENTOS PARA LACTENTES tem sua origem no CÓDIGO INTERNACIONAL DE COMERCIALIZAÇÃO DE SUBSTITUTOS DO LEITE MATERNO, aprovado pela Assembleia Mundial de Saúde, de 1981 (ORGANIZACIÓN MUNDIAL DE LA SALUD, 1981; BRASIL, 1993).

O Código Internacional foi elaborado a partir da percepção de que as pressões comerciais estavam desestimulando e interferindo no aleitamento materno, fato este denunciado na Assembléia da OMS de 1980, como já mencionado. Criado para restringir e acabar com as muitas práticas de venda e propaganda usadas na comercialização de alimentos infantis, mamadeiras e chupetas, ou qualquer outro artefato que venha a interferir no aleitamento materno. Em sua votação, teve apenas um voto contrário, dos Estados Unidos da América, preocupados com o efeito negativo que este poderia ter sobre o comércio americano. O Código Internacional constitui-se em recomendação da OMS para que os governos o adaptem e implantem segundo as circunstâncias nacionais (BRASIL, 1991; BRASIL, 1993).

A NORMA BRASILEIRA PARA COMERCIALIZAÇÃO DE ALIMENTOS PARA LACTENTES, teve sua elaboração concluída em 1988, e sua aprovação final sob a designação de Resolução 31/92 do Conselho Nacional de Saúde, em 12 de outubro de 1992. Como tal, tem força de lei e prevê sanções a seus infratores. O Brasil é um dos 11 países que teve a iniciativa de elaborar e aprovar sua NORMA (BRASIL,1993).

Com a aprovação da NORMA e seu efetivo cumprimento, espera-se que diminuam as pressões criadas pela publicidade e promoção comercial dos produtos e artefatos de aleitamento artificial, criando dessa forma, uma condição favorável para que a amamentação volte a ser percebida como uma prática habitual. 
Outro elemento de análise importante, no caminhar da amamentação, como fator interferente na prevalência e duração do aleitamento materno, é o papel atribido ao trabalho assalariado que a mulher exerce fora do lar.

A situação do trabalho feminino em fábricas, criado a partir da Revolução Industrial, propiciou a utilização de substitutos do leite materno para a alimentação de crianças, filhos de operárias, contribuindo para a mudança no hábito natural da amamentação (FREYRE,1961).

Diante das condições sub-humanas do operariado no início do século, e em especial da condição feminina, no que tange ao trabalho da gestante e nutriz, é que surge em 1919 a Organização Internacional do Trabalho (OIT) com o objetivo de melhorar as condições de trabalho e de vida dos trabalhadores no mundo. Em sua primeira sessão, a OITestabeleceu uma recomendação referente ao emprego da mulher antes e após o parto. Este item estabelecia que as mulheres empregadas em empresas privadas, públicas ou comerciais teriam dois períodos de 30 min por dia, para amamentar o seu filho durante o expediente (HARDY;OSIS, 1991).

No decorrer das últimas décadas, obteve-se algumas conquistas quanto ao amparo legal das mulheres trabalhadoras e seu direito de amamentarem seus filhos. A legislação brasileira prevê, em seu Código Civil, algumas situações que asseguram à mulher dois descansos especiais durante sua jornada, para amamentar seu filho no próprio local de trabalho ou em creches mantidas pelas empresas. Prevê, também, o reembolso creche de livre escolha da empregada-mãe, pelo menos até seis meses de idade da criança (HARDY;OSIS, 1991).

Embora os avanços nas questões legais da amamentação sejam questionados quanto a sua abrangência e efetividade, maior preocupação nos causa, a desinformação da população, em especial das empregadas-mães quanto aos seus direitos. Esse fato deixa uma lacuna para que as empresas, livremente não assumam de fato sua parcela de responsabilidade no amparo ao aleitamento e, em conseqüência à saúde e direitos da criança. Fazendo-se, necessário, a nosso ver, que as leis sejam amplamente divulgadas pela mídia, além de uma fiscalização efetiva para não permitir os abusos e o desrespeito à lei e aos direitos do binômio mãe-filho.

Ao lado dos fatores já mencionados como elementos prejudiciais à prática do aleitamento materno, é consenso dos peritos no assunto que os serviços de saúde, mesmo que involuntariamente, vêm contribuindo para a diminuição da prevalência e duração da amamentação. Ao introduzirem rotinas e procedimentos que interferem com o estabelecimento e manutenção do aleitamento e não terem em sua maioria, a preocupação de definir uma política interna de incentivo à prática do amamentar, estes serviços têm tido um papel descompromissado com o binômio nas questões fundamentais da amamentação. 
Tentando superar esta questão, a Iniciativa Hospital Amigo da Criança, foi idealizada pelo UNICEF e OMS, tendo como objetivo a "promoção, proteção e apoio ao aleitamento materno". Essa Iniciativa faz parte da Declaração de Innocenti, documento firmado por representantes das Nações Unidas, representantes governamentais e de organizações não governamentais, em um evento realizado em agosto de 1990, em Spedale degli Innocenti, Florença, Itália, no qual se reconheceu a necessidade de que todos os países devem desenvolver políticas nacionais de aleitamento materno e estabelecer metas de curto e longo prazo para os anos 90 , para o efetivo restabelecimento da "cultura do aleitamento materno" (TAKE,s.d.; BRASIL, 1992).

Isto demonstra que o movimento pró-amamentação está passando por um processo de transformação, saindo do discurso idealista e distante da realidade materna, para a ação junto às mulheres e seus filhos.

A Iniciativa Hospital Amigo da Criança contempla ações que devem ser adotadas pelos serviços que oferecem assistência obstétrica e cuidados a recém-nascidos, com o objetivo de facilitar o início precoce da amamentação, assim como sua continuidade. Este trabalho deve garantir o contato constante da mãe e filho, orientação e apoio às nutrizes para o manejo da amamentação, bem como uma filosofia única de assistência através de ajuste de rotinas e práticas, como também de suas atitudes e comportamentos, daqueles que prestam assistência ao binômio, a fim de garantir a adoção dos Dez Passos para o Sucesso do Aleitamento Materno (TAKE,s.d; BRASIL, 1992).

A iniciativa de efetivo trabalho junto às instituições prestadoras de serviços ao binômio mãe-filho, vem de encontro à necessidade de fortalecer a estratégia adotada, até então pelos programas oficiais de promoção ao aleitamento materno. Percebe-se, que embora as campanhas, ultimamente, tenham um cunho informativo de excelente qualidade, os serviços não oferecem, em sua maioria, retaguarda para as mulheres, principalmente quanto ao aspecto de discussão e resolução das dificuldades que venham a enfrentar na amamentação. As ações idealizadas para o incentivo ao aleitamento, nos parece, que não encontram ressonância nos serviços de saúde que deveriam estar prestando esse tipo de atendimento. Essa lacuna pode ser explicada, pelo fato de que os profissionais de saúde, em muitos casos, encontram-se despreparados para colocarem em prática as propostas dos programas pró-amamentação. Em geral, demonstram pouca experiência em trabalhar junto às mães, tendo dificuldades em oferecer apoio apropriado à mulher para o adequado manejo da amamentação (TAVARES, 1988; ORGANIZAÇÃO MUNDIAL DE SAÚDE, 1989).

Dessa forma, o preparo dos profissionais consiste em um elemento importante de análise da situação atual do perfil da prática do aleitamento materno, sendo um aspecto que deve ser modificado para o futuro. 
Uma pesquisa realizada pela Organização Panamericana de Saúde (OPS/OMS) constatou que apenas $1 \%$ da carga horária total dos cursos de graduação da áea da saúde são dedicados ao ensino do aleitamento materno (ESCOLAS, 1994).

Entre as recomendações feitas pelos membros da comissão que elaborou esta pesquisa, está a proposta de uma programação mínima sobre o ensino de aleitamento materno nos cursos de graduação da área da saúde (ESCOLAS, 1994).

Nesse sentido, percebe-se algumas iniciativas que visam suprir esta falha na formação dos profissionais, como o oferecimento de disciplinas optativas sobre aleitamento materno para complementação dos conteúdos disciplinares no curso de graduação da Escola de Enfermagem da USP (IDE, 1995).

Um outro fator nos chama a atenção nesta análise da prática da amamentação: é possível perceber no meio acadêmico, que o interêsse pelo aleitamento materno tem se tornado cada vez mais amplo, expandindo a argumentação científica dos atributos do leite materno e da importância da amamentação para mãe e filho.

Especialistas vêm discutindo o reflexo do desmame precoce quanto ao aparecimento de doenças crônicas como o Diabete Mellitus insulino dependente, que é uma doença au to-imune resultante da destruição de células das Ilhotas do pâncreas. KARJALAINEN et al (1992) colocam que esta doença pode ser desencadeada precocemente pela ingestão de fórmulas à base de leite de vaca. Os pesquisadores afirmam que parte da albumina do soro bovino (BSA) é responsável pela destruição das células pancreáticas, levando assim, à condições de desenvolver a doença.

Um estudo realizado na Finlândia demonstrou que crianças desmamadas antes de dois meses de idade apresentaram um risco de 1,5 vezes maior de desenvolver a doença, sendo que este foi 2 (duas) vezes maior quando os produtos lácteos foram introduzidos na dieta do recém-nascido antes dos dois meses de idade (VIRTANEN et al, 1993). Ambos os estudos, levam a concluir que evitando-se a exposição precoce do organismo da criança aos componentes do leite de vaca, pode-se evitar as condições favoráveis ao aparecimento da doença, ressaltando a proteção oferecida pelo leite materno em mais este aspecto da saúde do ser humano.

Também os fonoaudiblogos e ortodontistas vêm enfatizando o papel que a dinâmica de suç̧ão, feita pelo recém-nascido no peito materno, representa para o des envolvimento adequado dos órgãos fono-articulatórios da criança, tomando-se como ponto de partida a evolução e maturação dessas estruturas.

Sugar é um ato que envolve o trabalho de vários grupos musculares da região oral. A ação coordenada dos bucinadores, dos orbicularis, da língua e do palato mole na sucção, além de desempenhar uma função, também promove 
a exercitação desta musculatura, promovida pela movimentação de elevação e abaixamento e antero-posteriorização que o recém-nascido realiza durante a sucção ao peito. Toda essa "ginástica" possibilita o correto crescimento da mandibula, preparando as condições favoráveis para a erupção dos dentes e adequada oclusão. Além disso, propicia estímulos funcionais para um desenvolvimento harmonioso dos órgãos fono-articulatórios. A sucção, desta forma, favorece a adequação das estruturas, como um fator fundamental, também para a função da fala, propiciando a adequada articulação dos fonemas (LIMONGI, 1987; FERREIRA, 1989).

Paralelo a todas as questões que se pode levantar no sentido de fortalecer a prática da amamentação, um aspecto deve ser lembrado, em sua dimensão do passado, presente e futuro, que diz respeito aos fatores envolvidos na decisão materna de amamentar ou não. $O$ que temos até o momento é uma visão de fatores como o nível sócio-econômico, idade materna, número de filhos, experiências anteriores, influência de parentes e profissionais, práticas e rotinas hospitalares que interferem na decisão materna de alimentar o filho. Portanto, parece-nos que os fatores de prevalência e manutenção da amamentação são parcialmente conhecidos.

Fatores estes que aparentemente, até hoje, não foram atingidos pelas campanhas de incentivo ao aleitamento materno, uma vez que a promoção da amamentação tem sido baseada principalmente na informação sobre os aspectos biológicos e técnicos, dissimulados em uma linguagem abusiva de significados afetivos. Este tipo de estratégia tem trazido inúmeras dificuldades para a mulher, principalmente em nível do seu emocional, quando ao encarar a amamentação como algo perfeitamente possível de ser realizada por ela, pode deparar com situações que não saberá como superar. Na maioria das vezes não encontra auxílio para atender suas necessidades.

Observamos em nossa experiência que muitas vezes, o conhecimento da mulher sobre o processo da lactação e técnicas da amamentação contribuem para que ela supere obstáculos e dificuldades e continue amamentando seu filho; por outro lado, para outras mulheres, as mesmas estratégias educacionais podem não oferecer os mesmos resultados, demonstrando que estas necessitam mais do pessoal do que apenas informação.

A maioria dos trabalhos, ao estudar as questões da amamentação, restringem-se em listar fatores externos de causa de desmame, aspectos isolados de características de personalidade materna e relacioná-los ao fato da mulher exercer ou não as ações técnicas do amamentar.

A literatura sobre as questões da amamentação indicam que as variáveis que influenciam tanto o desmame como a persistência das mulheres em manter o aleitamento materno são múltiplas. PRIDHAM et al, (1989) afirmam que os estudos sobre a amamentação apontam existir um significado encoberto para as mães, o qual ainda não foi percebido e que pode direcionar as decisões delas quanto ao amamentar. 
BOTTORFF (1990) afirma que decidir por amamentar implica em embrenhar rumo ao desconhecido. A mulher estabelece metas, planeja, mas as decisões s6 serão definidas quando ela se vê na situação de amamentar. Na presença do filho e no ato de amamentar, a mulher passa a experienciar seu mundo de uma nova maneira. Embora o aleitamento materno possa parecer de simplicidade "técnica" singular, ele se apresenta no dia-a-dia, para a prática assistencial de uma complexidade ainda não desvendada, ocultando por certo as razões reais de tão diferentes situações de amamentação para cada mulher e seu filho, em particular.

É nessa linha de raciocínio que algumas pesquisas vêm construindo uma nova compreensão do processo de amamentar.

SILVA (1994) concluiu em seu estudo que a experiência de amamentar é percebida pela mulher como um processo que se expande e reflete nas demais interações de sua vida, no qual suas percepções sofrem modificações ao longo do curso dessa vivência, num constante movimento, não estando, portanto centrada em uma interação bilateral mãe-filho. Nesse processo, a mulher identifica-se pesando riscos e beneficios, onde ela os interpreta, segundo sua perspectiva. Os riscos, assim como os benefícios, identificados e simbolicamente assim interpretados, são aquilatados pela mulher tanto em relação à criança, quanto em relação a si mesma.

Assim, amamentar é constituído por facetas que se mostram nos diferentes momentos da vivência da mulher-mãe (ARANTES, 1991).

Esse pensar em relação à amamentação leva-nos a refletir sobre a necessidade de um modelo assistencial que contemple a compreensão dos elementos determinantes da decisão materna, além da esfera da interação mãe-filho, implicando em uma assistência abrangente e holística, compreendendo a mulher na sua totalidade.

Percebe-se assim, que além das alternativas de esforço de qualificação profissional e mudanças institucionais para melhor atendimento da mulher na fase de amamentação, do efetivo engajamento dos profissionais em fazer cumprir as leis que o país dispõe para proteção ao aleitamento, das pesquisas que embasam o valor do leite humano e a função da sucção ao peito materno, é necessário um olhar mais profundo e abrangente para a identificação dos elementos avaliativos e estimativos que norteiam a mulher-mãe rumo da amamentação.

A instrumentalização da mulher, no âmbito das habilidades técnicas e conhecimentos sobre a amamentação, não dever ser abandonada, mas antes, ser vista como um instrumento auxiliar na assistência e não um fim em si mesma. Para isso é preciso uma nova leitura da mulher e seu filho no contexto familiar e social e redimensionar o discurso e ações institucionais nas questões da amamentação (SILVA, 1994).

Acreditamos, que ao profissional de saúde 6 reservado a maior 
responsabilidade do sucesso de todas as alternativas de fomento à amamentação, e em especial ao profissional enfermeiro, por ser aquele que partilha da experiência materna convivendo com a mulher a maior parte do tempo, principalmente nos momentos iniciais e muitas vezes decisivos do processo de amamentar.

SILVA,I.A. Reflexions about breastfeeding's practices. Rev.Esc.Enf.USP,v.30, n.1,p.58-72, Apr. 1996.

The autor makes analises of breast feeding, doing a reflexion about the mainly indicators who has determined the atual situation, looking for identify ways for win the ideal cenary to future of breast feeding.

UNITERMS: Breastfeeding,

\section{REFERÊNCIAS BIBLIOGRÁFICAS}

ARANTES, C.I.S. O fenômeno amamentạ̧ão: uma proposta compreensiva. Ribeirão Preto, 1991, 86p. Dissertação (Mestrado) - Escola de Enfermagem de Ribeirāo Preto, Universidade de Såo Paulo.

BADINTER, E. Um amor conquistado, o mito do amor materno. 5.ed. Rio de Janeiro, Nova Fronteira, 1985.

BERQUÓ, E. et al. Caracterização e determinantes do aleitamento materno na Grande São Paulo e na Grande Recife. São Paulo, Centro Brasileiro de Análise e Planejamento, 1984 (Cadernos CEBRAP, 2).

BITTENCOURT, S.A. et al. Crescimento, diarréia e aleitamento materno: o caso da vila do Joðo. Cad. Saúde Pública, v. 9, n. 07-13, 1993. Suplemento.

BOTTORFF, J.L. Persistence in breastfeeding: a phenomenological investigation. J. Adv. Nurs., v. 15, n. 2. p. 201-9, 1990

BRASIL. Ministério da Saúde. Instituto Nacional de Alimentação e Nutrição. Oprograma Nacional de alimentação e Nutrição - PRONAN: Suas bases e a participação setorial. Brasília. 1982.

Ministério da Saúde. Instituto Nacional de Alimentação e Nutrição. Programa Nacional de Incentivo ao Aleitamento Materno. Brasília, 1991.

Programa Nacional de Incentivo ao Aleitamento Materno. Grupo de Defesa da Saúde da Criança. Hospitais Amigos das Crianças: Plano de Ação. Brasília, 1992./mimeografado/. 
BRASIL. Ministério da Saúde. Instituto Nacional de Alimentaçào e Nutrição. Conselho Nacional de Saúde. Norma brasileira para comercialização de alimentos para lactentes. 2.ed. Brasília, 1993.

CAVALCANTI, M.L.F. Conhecimentos, atitudes e práticas de pessoal de saúde sobre aleitamento materno. São Paulo, 1982.439p. Tese (Doutorado) - Faculdade de Saúde Pública, Universidade de São Paulo.

ESCOLAS nāo ensinam Aleitamento Materno: faltam carga horária e bibliografia atualizada sobre o assunto. Boletim Nacional de Iniciativa Hospital Amigo da Criança, n. 9, p. 2, 1994

DONAHUE,M.P. Nursing the finest art. An illustraded history. Mosby Company , Missouri, 1985.

FADUL, F.R. et al. Fatores que contribuem para o desmame precoce. Rev.Bras.Enf., v. 36, n. 2, p. $213-20,1983$.

FERREIRA, L.P. Temas de fonoaudiologia. 3. ed. São paulo, Loyola, 1989.

FREYRE, G. Casa Grande e senzala. Rio de Janeiro, Livraria José Olympio Editora, 1961.

GOLDENBERG, P. Repensando a desnutrição como questão social. Campinas, Editora da UNICAMP, 1988.

HARDY, E.E.; OSIS, M.J. Mulher trabalho e amamentação: legislação e prática. Campinas, Editora da UNICAMP, 1991.

IDE, C.A.C. Graduação em enfermagem: a configuração do novo currículo da Escola de Enfermagem da USP. Rev.Esc.Enf.USP, v. n.p. 1995/no prelo/.

KARJALAIMEN, J. et al. A bovine albumin peptide as a possible trigger of insulin-dependent diabets mellitus. The New England Journal of Medicine, v. 327, p. 302-307, 1992.

LIMONGI, S.C.O. Consideraçòes sobre a importancia dos aspectos morfo-fisiológicos e emocionais no desenvolvimento e profilaxia dos órgaos fono-articuladores. In: LACERDA, E.T.; CUNHA, M.C. Sistema sensório motor oral: perspectivas de avaliação e terapia. São Paulo, PUC-SP., 1987

MONCAU, J.E.C. et al. Prática do aleitamento materno em unidade básica de saúde nos anos de 1989 e 1990. Ars. Curandi, v. 26, n. 5, p. 90-7, 1993.

MOTA, J.A.C. Ideologia implicada no discurso da amamentaça materna e estudo retrospectivo comparando crescimento e morbidade de lactentes em uso de leite humano e leite de vaca. Belo Horizonte, 1990. 226p. Dissertação (Mestrado) - Faculdade de Medicina, Universidade Federal de Minas Gerais.

ORGANIZACIÓN MUNDIAL DE LA SALÚD. 27a. Assembléia mundial de la salúd. Bol. Of Sanit. Panam., v. 77, n. 2, p. 171-8, 1974.

33a. Assemblea mundial de la salúd. Bol. Of. Sanit. Panam., v. 89, n. 2, p. 176-8, 1980. 
Comercializacion de sucedaneos de la leche materna. Bol. Of. Sanit. Panam., v. 91, n. 5 , p. 441-8, 1981.

ORGANIZAÇĀO MUNDIAL DA SAÚDE. Proteção, promoção e apoio ao aleitamento materno: o papel especial dos serviços materno-infantis - uma declaração conjunta OMS/UNICEF. Genebra, 1989.

PRIDHAM, K.F. et al. Mothers' working models of infant feeding: description and influencing factors. J. Adv. Nurs., v. 14, n. 2, p. 1051-61, 1989.

RAMOS, NETO, M.O. et al. Estudo do aleitamento. Rev.Esc.Enf.USP., v. 12, n. 2, p. 77-100, 1978.

SEPÚLVEDA, D. et al. Lactância materna: alguns fatores psicosociales y biológicos que la influenciam. Bol. Of. Sanit. Panam., v. 95, n. 1, p. 51-9, 1983.

SIGULEM, D.M.; TUDISCO, E.S. Aleitamento natural em diferentes classes de renda no município de São Paulo, Arch. Latino Am. Nutr. v. 30, p. 400-16, 1980.

SILVA, A.A.M. Amamentação: fardo ou desejo? Estudo histórico-social dos saberes sobre aleitamento na sociedade brasileira. Ribeirão Preto, 1990. 302 p. Dissertação (Mestrado) Faculdade de Medicina de Ribeirão Preto, Universidade de São Paulo.

SILVA, I.A Amamentar: uma questão de assumir riscos ou garantir benefícios. São Paulo. 1994. 198p. Tese (Doutorado) - Escola de Enfermagem, Universidade de Såo paulo.

TAKE the baby friendly iniciative: a global effort with hospitals, health services and parents to breastfeed babies for the best start in life. New York, UNICEF, s.d.

TAVARES, C.M.A. Avaliação de atividades de incentivo ao aleitamento materno: estudo realizado junto à Secretaria de Estado de Saúde de Mato Grosso, 1985/1987. São Paulo. 1988 p. Dissertação (Mestrado) - Escola de Enfermagem. Universidade de São Paulo.

TERUYA, K.M. et al. Centro de lactação de Santos: promoção, treinamento e pesquisa em amamentaçào. J. Pediatr., v. 68 , n. 5/6, p. 186-88, 1992

VIRTANEN, S.M. et al. Early introduction of dairy products associated with increased risk of IDDM in Finnish Childre, Diabetes, v. 42, p. 1786-1790, 1993. 